\title{
Outcomes after peritoneal dialysis catheter placement by laparoscopic surgery versus open surgery: systematic review and meta- analysis
}

Tsutomu Sakurada ${ }^{1,2^{*}}$ D, Atsushi Ueda ${ }^{1,3}$, Daisuke Komukai ${ }^{1,4}$, Kiyotaka Uchiyama ${ }^{1,5}$, Yasushi Tsujimoto ${ }^{1,6}$, Hidemichi Yuasa ${ }^{1,7}$, Munekazu Ryuzaki ${ }^{1,8}$, Yasuhiko Ito ${ }^{1,9}$, Masashi Tomo ${ }^{1,10}$ and Hidetomo Nakamoto ${ }^{1,11}$

\begin{abstract}
Success in peritoneal dialysis (PD) requires a well-functioning catheter, and catheter placement at PD initiation is extremely important for long-term PD. Although several randomized, controlled trials (RCTs) have compared open surgery with laparoscopic surgery, there is controversy regarding which surgical approach is desirable. The present systematic review and meta-analysis was performed to clarify which surgical approach is superior. A systematic literature search for RCTs was performed using the Cochrane Central Register of Controlled Trials and the MEDLINE database, and a meta-analysis was performed using Review Manager Version 5.3.5 (Cochrane Collaboration, Oxford, UK). Catheter survival was the primary outcome, and leakage, hernia, requirement for reoperation, catheter-related infection, postoperative pain, hospitalization period associated with catheter placement, and catheter migration were the secondary outcomes. After screening 913 references, seven RCTs were analyzed. Laparoscopic surgery was found to have no favorable effect on catheter survival (5 trials, 424 patients; risk ratio [RR] 1.02; 95\% confidence interval [Cl] $0.92-1.13 ; p=0.68$; low-quality evidence]. The incidence of catheter migration was significantly lower with laparoscopic surgery ( 6 trials, 526 patients; RR $0.42 ; 95 \% \mathrm{Cl} 0.18-0.96 ; p=0.04$; moderate-quality evidence). However, the significance decreased on limiting the analysis to RCTs involving laparoscopic surgery without secured suture of the PD catheter (4 trials, 431 patients; RR 0.58; 95\% Cl 0.27-1.25; $p=0.17$; moderate-quality evidence). Other outcomes were similar between open surgery and laparoscopic surgery. The present findings indicate that laparoscopic surgery has a limited advantage over open surgery with respect to PD patients' outcomes.
\end{abstract}

Keywords: Catheter migration, Catheter survival, Complication, Exit site infection, Peritonitis, Hernia, Leakage, Hospitalization

\section{Introduction}

In order for peritoneal dialysis (PD) to succeed, a wellfunctioning catheter is necessary. Therefore, accurate and safe catheter placement at the start of PD is extremely important for continued long-term PD. The catheter is placed by open surgery, laparoscopic surgery, or percutaneously. In general, there are many advantages

\footnotetext{
*Correspondence: sakurada@marianna-u.ac.jp

${ }^{1}$ Working Group on Revision of Peritoneal Dialysis Guidelines, Japanese Society for Dialysis Therapy, Tokyo, Japan

${ }^{2}$ Division of Nephrology and Hypertension, Department of Internal Medicine, St. Marianna University School of Medicine, Kanagawa 216-8511, Japan Full list of author information is available at the end of the article
}

of laparoscopic surgery over open surgery. First, it is cosmetically superior, and the risks of incisional hernia, surgical site infection, and bleeding are lower than with open surgery because of the small wound. Second, patients have much less discomfort and require fewer analgesics. Third, patients can get up and walk around sooner and get back to their regular activities earlier, thus shortening the length of hospital stay. Furthermore, laparoscopic surgery for PD catheter placement also has some advantages for surgeons. With laparoscopic surgery, the catheter can be placed in the pouch of Douglas while observing the tip of the catheter directly, and it is possible to prevent omental wrapping by omentectomy 
or omentopexy [1]. In addition, adhesiolysis can be performed with laparoscopic surgery for patients with adhesions, and hernia repair surgery can be performed simultaneously in patients with inguinal hernias.

As mentioned above, laparoscopes have various advantages, but they also have several disadvantages. One of the most important disadvantages is that laparoscopic surgery is extremely expensive because the instruments required to carry out the operation are very costly. In addition, the surgery also requires special skill, and not every hospital has specialized surgeons capable of performing it. Indeed, the incidence of laparoscopic surgery complications has also been reported to be directly proportional to the operator's experience [2]. Laparotomy can be performed with local anesthesia, but laparoscopic surgery requires general anesthesia. Furthermore, laparoscopic surgery is another risk factor for developing perioperative hypothermia due to prolonged surgical time and increased heat loss via exposure to cold/dry $\mathrm{CO}_{2}$ insufflation during pneumoperitoneum [3]. With respect to placement of the PD catheter, leakage of dialysate from the port is a concern. Although there have been several randomized, controlled trials (RCTs) comparing open surgery with laparoscopic surgery, there has been controversy as to which provides longer catheter survival and a low incidence of complications [4-10]. Therefore, a systematic review (SR) and meta-analysis were conducted to compare laparoscopic surgery with open surgery using the latest research results.

\section{Methods}

The protocol used for the systematic review and metaanalysis was registered in the UMIN Clinical Trials Registry (UMIN000033859). Exemption from the review was granted by the Ethics Committee because this study did not involve patient intervention and confidential personal data.

\section{Criteria for considering studies for this review Types of studies}

All RCTs and quasi-RCTs (RCTs in which allocation to treatment was obtained on alternate months) looking at the effects of different catheter placement techniques on patient outcomes in PD were included.

\section{Types of participants}

Adult patients initiating PD treatment were the target group.

\section{Types of interventions}

Studies comparing surgical placement by laparoscopic surgery or open surgery were included. Studies of percutaneous catheter placement were excluded.

\section{Types of outcome measures}

Primary outcome: Catheter survival [calculated by the number of participants who continued PD without removing the catheter at study completion [11]; data excluding death, transplantation, renal recovery, transfers to hemodialysis, and patient's choice to stop PD were analyzed.]

Secondary outcomes: Complications of catheter placement (early complications: leakage, late complications: hernia), PD catheter-related infection (exit site infection and tunnel infection), requirement for reoperation, postoperative pain, hospitalization period associated with catheter placement, catheter migration

\section{Search methods for identification of studies}

1. Relevant SRs and clinical practice guidelines (CPGs) were searched from the Cochrane Central Register of Controlled Trials (CENTRAL) and MEDLINE database up to April 10, 2018.

2. All RCTs referred to in those SRs and CPGs were included in the analysis.

3. Additionally, RCTs were obtained from CENTRAL and MEDLINE (from April 2004 to April 21, 2018) and combined with a search strategy for the identification of RCTs. The papers before April 2004 were exempted from this secondary search because a thorough search of RCTs based on the Cochrane library was performed by Strippoli et al. 2004 [12].

4. There was no language restriction. Search terms used in this review are summarized in the Appendix.

\section{Data collection and analysis}

This review was undertaken by four authors (T.S., D.K., K.U., and A.U.). The search strategy described was used to obtain titles and abstracts of studies relevant to the review. The titles and abstracts were screened independently by T.S. and D.K. in the primary search for SRs and CPGs, and by K.U. and A.U. in the secondary search for RCTs. Studies that were not relevant based on the inclusion criteria were discarded. Two authors independently assessed the retrieved abstracts, and, if necessary, the full texts of these studies to determine which studies were eligible for inclusion.

\section{Data extraction and management}

Data extraction was performed independently by the same authors using standard data extraction forms. Preceding the assessment, studies reported in non-English language journals were translated by a translation service, GLOVA Co. (Tokyo, Japan). Disagreements were resolved in consultation with H.Y.

\section{Assessment of risk of bias in included studies}

The following items were independently assessed by four authors (T.S., K.U., D.K., and A.U.) using the risk of bias 
assessment tool, as previously described [13], and discrepancies were resolved by consultation with H.Y. and Y.T.: random sequence generation (selection bias), allocation concealment (selection bias), blinding of participants and personnel (performance bias), blinding of participants and personnel (detection bias), incomplete outcome data (attrition bias), selective reporting (reporting bias), and other bias.

\section{Measures of treatment effect}

Data from each trial was analyzed using the risk ratio (RR) with 95\% confidence intervals (CI) for dichotomous outcomes (e.g., catheter failure, infection, and migration) and using the mean difference (MD) for continuous outcomes (pain scale and hospitalization period).

\section{Data synthesis}

Summary estimators of treatment effects were pooled using the random-effects model by Review Manager Software (RevMan version 5.3.; Cochrane Collaboration, Oxford, UK). In individual studies, when the outcomes were measured at several time points, the data closer in time among the studies were chosen. In analysis of catheter migration, a sub-analysis according to with or without secured suture of the catheter was performed, because fixation of the catheter in the abdominal cavity could affect the outcome.

\section{Assessment of heterogeneity}

Heterogeneity of treatment effects was evaluated using the chi-squared test, with $\mathrm{N}-1$ degrees of freedom, with an alpha of 0.05 considered significant, and with the $I^{2}$ test [14].

\section{Assessment of the certainty of evidence}

The overall certainty of evidence related to each of the main outcomes was assessed using the GRADE (Grades of Recommendation, Assessment, Development and Evaluation) approach [15]. The quality of a body of evidence was rated as high, moderate, low, or very low certainty, with respect to risk of bias, inconsistency, indirectness, imprecision, and publication bias.

\section{Results}

\section{Study selection and data management}

A total of 122 titles of reported CPGs and SRs were identified through the CENTRAL and MEDLINE literature search, and ten CPGs and SRs were extracted. These CPGs and SRs were reviewed, and six RCTs were extracted. Although an attempt was made to search recent RCTs using the search strategy described in the most recent SR reported by Qiao et al. in 2016 [9], the formula was incomplete. Thus, it was decided to re-search for RCTs after 2004 when the Cochrane Review was reported by Strippoli et al. [12]. A total of 913 references were initially screened, of which 601 had no duplicates and 594 were rejected on title and abstract review. Finally, seven RCTs were identified. After full-text review, all seven RCTs were entered into the analysis (Fig. 1).

\section{Study characteristics}

The characteristics of the included studies are shown in Tables 1 and 2. A total of 571 patients from seven RCTs published from 1999 to 2018 were included. The number of patients per study was at most 148 and at least 45. Laparoscopic surgery included peritoneoscopic placement and advanced laparoscopic surgery with adhesiolysis as needed. Although fixation of the catheter into the abdominal cavity was performed in two laparoscopic surgeries, it was not performed in all open surgeries. Preoperative antibiotics were given in five RCTs.

\section{Risk of bias}

The assessment of risk of bias of the included studies is shown in Fig. 2. Three RCTs did not describe the methods of randomization. The risk of bias domains of random sequence generation and allocation concealment were considered "low" with the sealed envelope method in three RCTs, "high" with the alternative month method in one RCT, and "unclear" for those that were not described.

The domain of blinding of participants and personnel was described in only one RCT, but its blinding was limited to the method of dressing after operation, which was applied in the same positions for all patients to blind the ward staff to the technique used (low). Five RCTs were not blinded to participants and personnel (high), and one RCT did not describe the domain (unclear). The domain of blinding of outcome assessment was not described in all seven RCTs (unclear). In one RCT, many participants could not be traced due to drop-outs or deaths. Therefore, the domain of incomplete outcome data was considered "high." Reporting bias was not identified in seven RCTs. Because it was suspected that two RCTs had severe bias in the background characteristics between the groups, the domain of "other bias" was considered "high."

\section{Effect of interventions}

The quality of evidence of each study and outcomes are presented as a summary of findings table (Table 3). Laparoscopic surgery made no difference to catheter survival (five trials, 424 patients; RR, 1.02; 95\% CI, 0.92 to 1.13 , $I^{2}=58 \%$; low quality evidence), complications of catheter placement [early complications: leakage (seven trials, 571 patients; RR, 0.86 ; $95 \% \mathrm{CI}, 0.25$ to $3.02, I^{2}=52 \%$; very low quality evidence), late complications: hernia (four trials, 391 patients; RR 0.75 ; $95 \% \mathrm{CI}, 0.21$ to $2.72, I^{2}=0 \%$; very low-quality evidence)], PD catheter-related infection (exit site infection and tunnel infection) (four trials, 262 patients, RR 0.99 ; $95 \% \mathrm{CI}, 0.43$ to $2.29, I^{2}=0 \%$; low-quality 


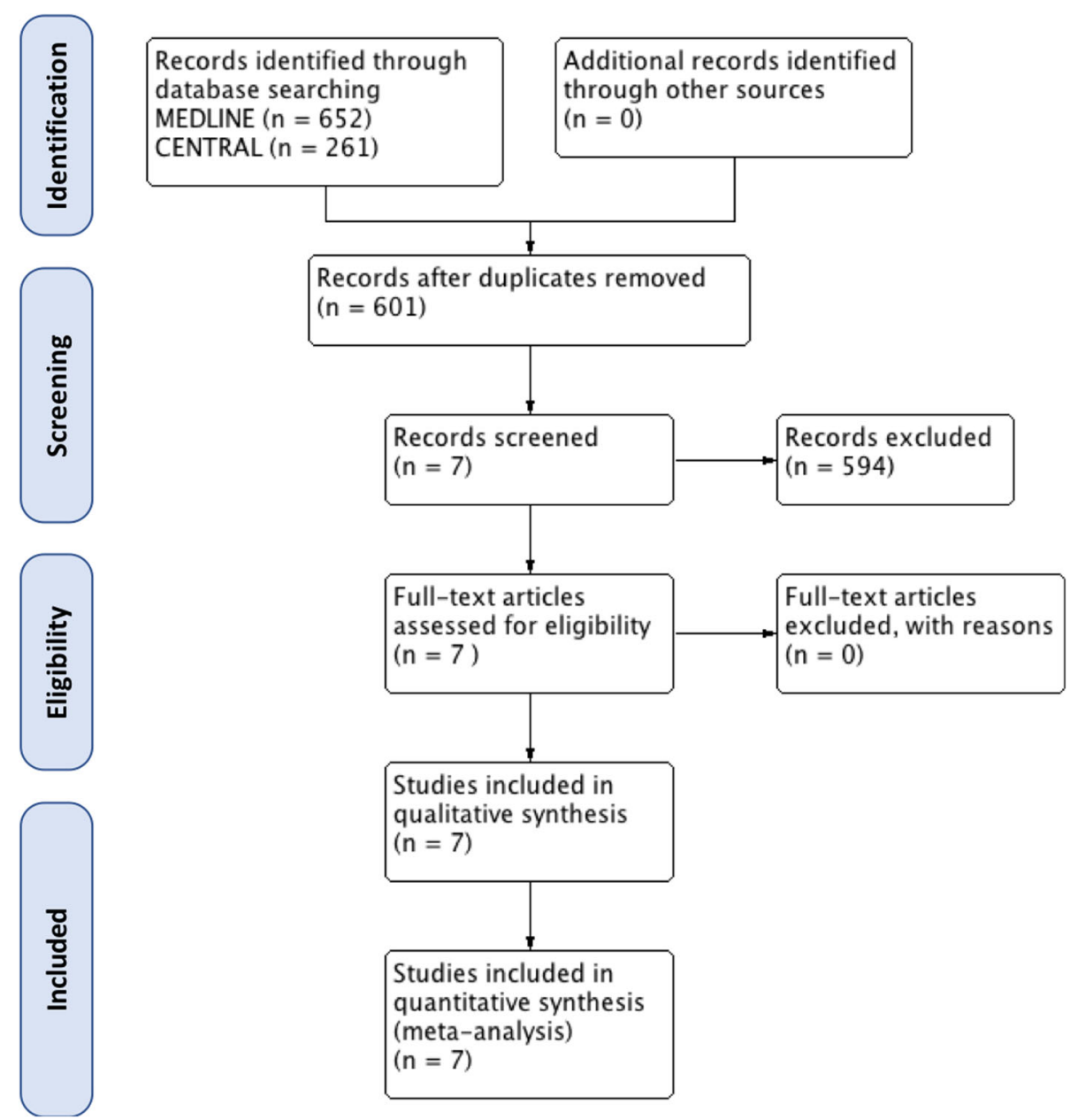

Fig. 1 PRISMA flow diagram of the systematic literature search

evidence), and requirement for re-operation (one trial, 90 patients; RR 0.96 ; $95 \%$ CI 0.39 to 2.33 ; moderate-quality evidence) compared with open surgery (Fig. 3a-c, Fig. 4a). There were significant heterogeneities in catheter survival and leakage. Postoperative pain evaluated based on the number of patients who complained of pain may have been better with laparoscopic surgery (two trials, 127 patients; RR 1.05 ; $95 \%$ CI 0.80 to $1.39, I^{2}=0 \%$; very lowquality evidence) (Fig. 4 (B-1)). On the other hand, postoperative pain assessed by a pain scale did not differ between the groups (one trial, 45 patients; mean difference, - 1.00; CI - 2.24 to 0.24; very low-quality evidence) (Fig 4 (B-2)). The hospitalization period associated with catheter placement was better in open surgery (three trials, 212 patients; mean difference, 0.83 ; CI 0.04 to $1.61, I^{2}=0 \%$; very low-quality evidence) than in laparoscopic surgery (Fig. 4c). There was a significant benefit in catheter migration in laparoscopic surgery compared with open surgery (6 trials 526 patients; RR 0.42; 95\% CI 0.18 to $0.96, I^{2}=24 \%$; moderate-quality evidence).
However, the significance diminished on limiting the analysis to RCTs involving laparoscopic surgery without secured suture of the PD catheter (4 trials, 431 patients; RR 0.58; 95\% CI $0.27-1.25, I^{2}=9 \% ; p=0.17$; moderatequality evidence) (Fig. 4d).

\section{Discussion}

In this review, it was uncertain whether laparoscopic surgery has beneficial effects on important outcomes such as catheter survival, complications of catheter placement, late complications, and PD catheter-related infection because the certainty of the evidence reviewed was very low to moderate. Although the incidence of catheter migration was significantly lower with laparoscopic surgery, laparoscopic surgery with secured suture of the PD catheter had a positive impact on outcomes.

Numerous RCTs [4-10] and observational studies [16-25] comparing open surgery and laparoscopic surgery for PD catheter placement have been published since the late 1990s. Several SRs and meta-analyses have 


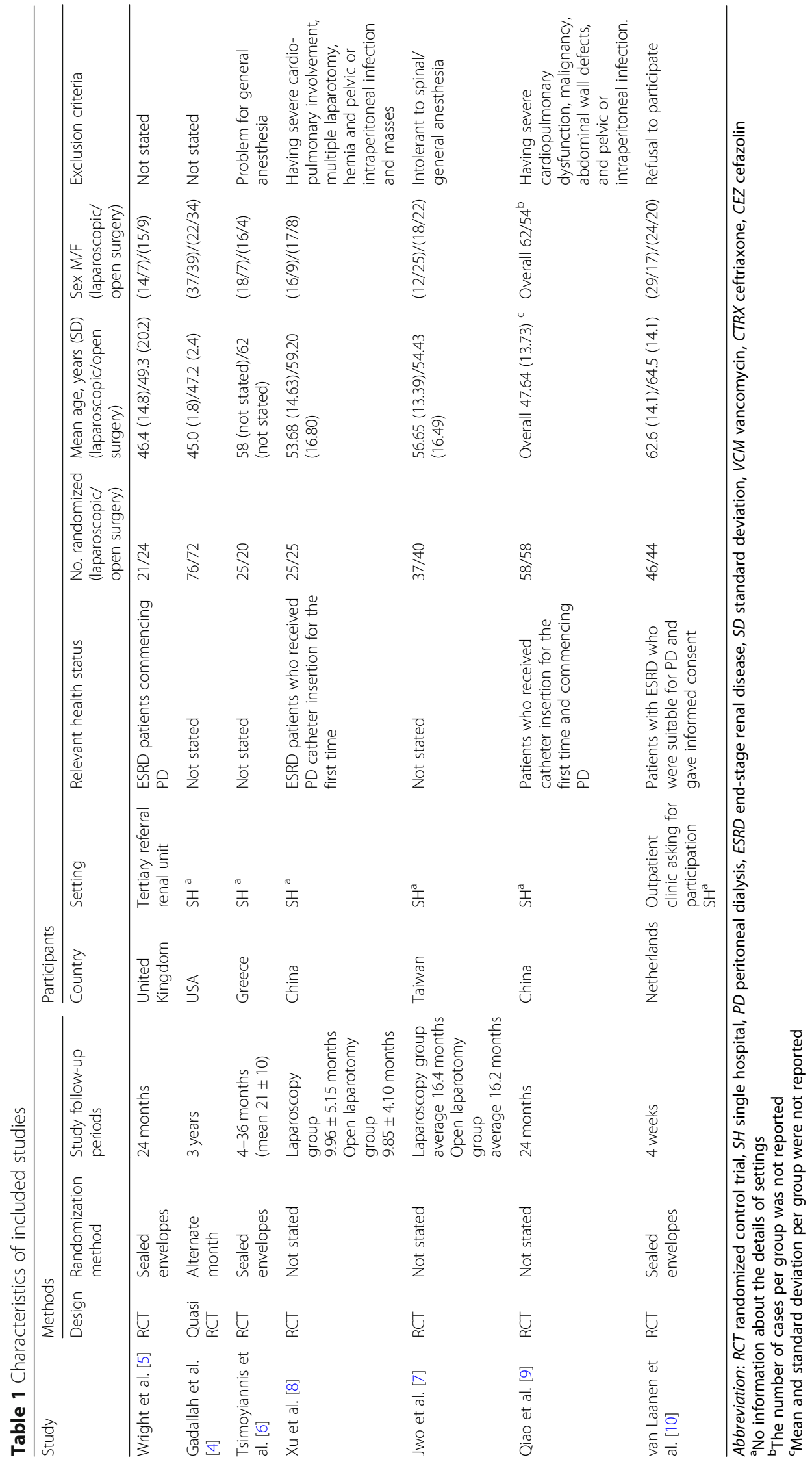


Table 2 Characteristics of included studies

\begin{tabular}{|c|c|c|c|c|c|}
\hline \multirow[t]{2}{*}{ Study } & \multicolumn{4}{|l|}{ Interventions } & \multirow[t]{2}{*}{ Outcomes } \\
\hline & Treatment group & $\begin{array}{l}\text { Control } \\
\text { group }\end{array}$ & $\begin{array}{l}\text { Details of intervention in the laparoscopic surgery } \\
\text { group }\end{array}$ & $\begin{array}{l}\text { Preoperative } \\
\text { antibiotics }\end{array}$ & \\
\hline Wright et al. [5] & $\begin{array}{l}\text { Laparoscopic } \\
\text { technique }\end{array}$ & $\begin{array}{l}\text { Open } \\
\text { surgery }\end{array}$ & & VCM $2.0 \mathrm{~g}$ & $\begin{array}{l}\text { Fluid leak } \\
\text { Pain scores after } \\
\text { operation } \\
\text { Exit site infection } \\
\text { Duration of } \\
\text { hospitalization }\end{array}$ \\
\hline Gadallah et al. [4] & Peritoneoscopy & $\begin{array}{l}\text { Open } \\
\text { surgery }\end{array}$ & $\begin{array}{l}\text { Using Y-TEC peritoneoscopic technique. } \\
\text { Peritoneoscopically-placed catheters were } \\
\text { implanted under local anesthesia. }\end{array}$ & VCM $1.0 \mathrm{~g}$ & $\begin{array}{l}\text { Catheter survival } \\
\text { Dialysate leak } \\
\text { Hernia } \\
\text { Catheter migration }\end{array}$ \\
\hline Tsimoyiannis et al. [6] & $\begin{array}{l}\text { Laparoscopic } \\
\text { placement }\end{array}$ & $\begin{array}{l}\text { Open } \\
\text { surgery }\end{array}$ & $\begin{array}{l}\text { The catheter was secured to the back wall } \\
\text { of the uterus or bladder with } 2 / 0 \text { polypropylene. } \\
\text { Five patients who underwent previous } \\
\text { laparotomies had an extended adhesiolysis } \\
\text { performed before catheter placement. }\end{array}$ & Not stated & $\begin{array}{l}\text { Dialysate leak } \\
\text { Catheter migration }\end{array}$ \\
\hline Xu et al. [8] & $\begin{array}{l}\text { Laparoscopic } \\
\text { placement }\end{array}$ & $\begin{array}{l}\text { Open } \\
\text { surgery }\end{array}$ & $\begin{array}{l}\text { The catheter was secured to the back wall of } \\
\text { the uterus or bladder with } 3 / 0 \text { polypropylene. }\end{array}$ & CTRX $1.0 \mathrm{~g}$ & $\begin{array}{l}\text { Catheter survival } \\
\text { Dialysate leak } \\
\text { Hernia } \\
\text { Exit site infection } \\
\text { The number of pain } \\
\text { complaint patients } \\
\text { Catheter migration }\end{array}$ \\
\hline Jwo et al. [7] & Laparoscopic & $\begin{array}{l}\text { Open } \\
\text { surgery }\end{array}$ & $\begin{array}{l}\text { Laparoscopic adhesiolysis was performed for those } \\
\text { who had peritoneal adhesions due to previous } \\
\text { abdominal surgery or pelvic inflammatory disease. }\end{array}$ & CEZ $0.5 \mathrm{~g}$ & $\begin{array}{l}\text { Catheter survival } \\
\text { Dialysate leak } \\
\text { Hernia } \\
\text { Exit site infection } \\
\text { The number of pain } \\
\text { complaint patients } \\
\text { Duration of } \\
\text { hospitalization } \\
\text { Catheter migration }\end{array}$ \\
\hline Qiao et al. [9] & $\begin{array}{l}\text { Catheter implantation } \\
\text { with laparoscopy }\end{array}$ & $\begin{array}{l}\text { Open } \\
\text { surgery }\end{array}$ & & Not stated & $\begin{array}{l}\text { Catheter survival } \\
\text { Dialysate leak } \\
\text { Hernia } \\
\text { Catheter migration }\end{array}$ \\
\hline van Laanen et al. [10] & $\begin{array}{l}\text { Laparoscopic } \\
\text { technique }\end{array}$ & $\begin{array}{l}\text { Open } \\
\text { surgery }\end{array}$ & $\begin{array}{l}\text { Only in case of insufficient space in the lower } \\
\text { abdomen for a good position of the catheter was } \\
\text { adhesiolysis performed. }\end{array}$ & CEZ $1.0 \mathrm{~g}$ & $\begin{array}{l}\text { Catheter survival } \\
\text { Dialysate leak } \\
\text { Exit site infection } \\
\text { Re-operation } \\
\text { Duration of } \\
\text { hospitalization } \\
\text { Catheter migration }\end{array}$ \\
\hline
\end{tabular}

Abbreviation: $R C T$ randomized control trial, $S H$ single hospital, $P D$ peritoneal dialysis, ESRD end-stage renal disease, $S D$ standard deviation, VCM vancomycin, $C T R X$ ceftriaxone, CEZ cefazolin

${ }^{a}$ No information about the details of settings

${ }^{\mathrm{b}}$ The number of cases per group was not reported

'Mean and standard deviation per group were not reported

been conducted to determine whether laparoscopic surgery or open surgery is the optimal surgery since 2012 [26-29]. Unfortunately, the studies showed nonuniform results, and the recommended surgical procedure has not been clear. However, most RCTs included in the meta-analysis were performed more than 10 years ago. In 2018, the latest RCT on this topic was reported by van Laanen et al. [10]; therefore, the present metaanalysis and systematic review included this research.

In the present meta-analysis results, PD catheter survival was not significantly different between laparoscopic surgery and open surgery. According to the latest guidelines, catheter patency is defined as the percentage or probability of catheter survival at 12 months following placement [30]. The factors affecting catheter survival were defined as some type of intervention (surgical or radiological) on the catheter due to flow dysfunction or irremediable drain pain. In addition, the guidelines clearly state that catheter patency at 12 months should be higher than $80 \%$ for basic laparoscopic surgery or open surgery. However, only two of five RCTs showed catheter patency higher than $80 \%$ at 12 months. One of the remaining three 


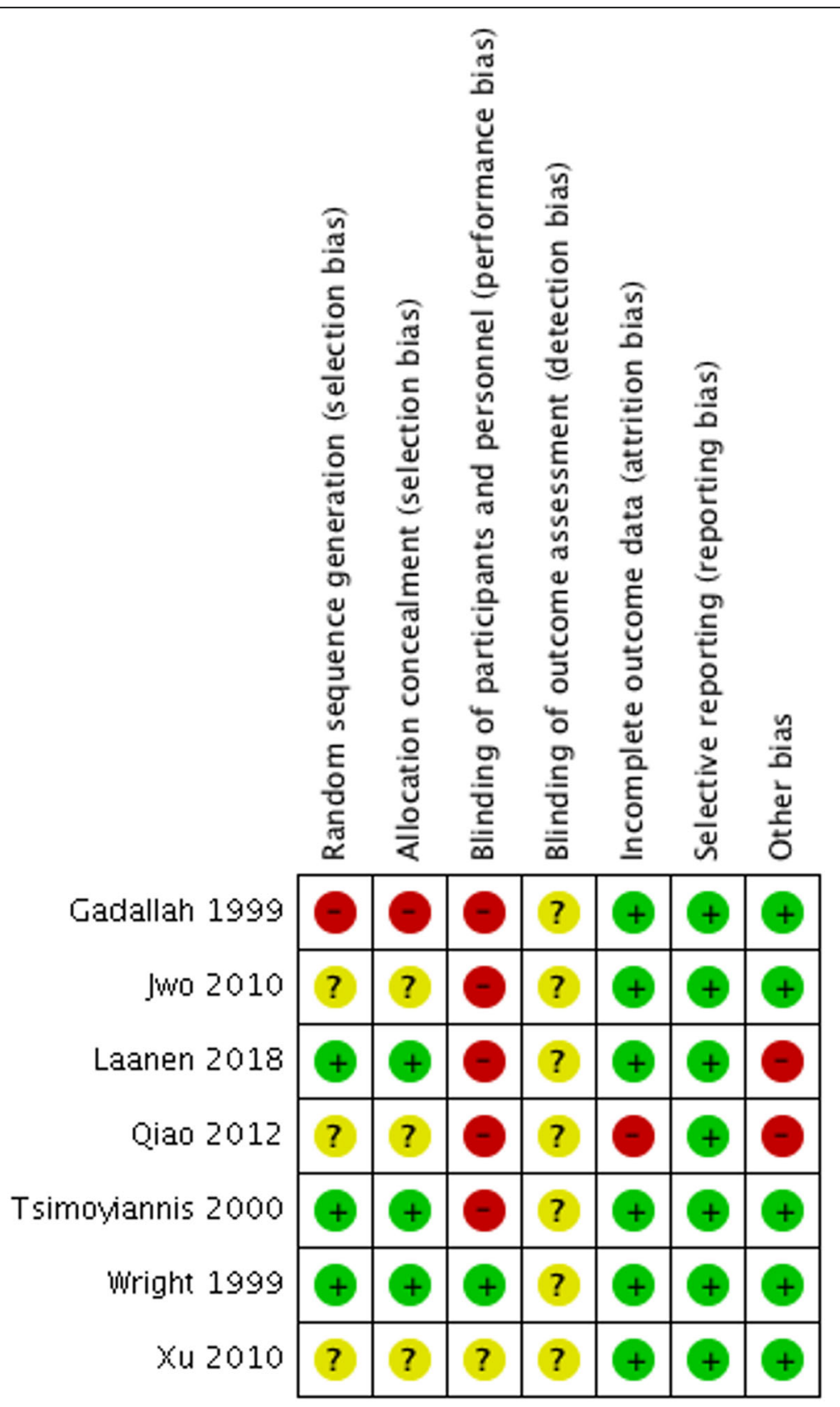

Fig. 2 Risk of bias summary graph of the included studies

RCTs had an average observation period of only 10 months, and the other two RCTs did not reach $80 \%$ catheter patency at 12 months for both laparoscopic surgery and open surgery. However, the RCT by van Laanen et al. included catheter removal due to catheter-related infection as an event in the analysis of catheter patency, which may have resulted in low catheter survival [10]. Previous SRs and meta-analyses have shown that catheter survival in the laparoscopic surgery group was significantly superior to that in open surgery, but these studies (Hagen et al.
[27], Chen et al. [28], and Qiao et al. [29]) included some observational studies.

There was no difference in complications of catheter placement between laparoscopic surgery and open surgery. This result was similar to previous SRs and metaanalyses. Although laparoscopic surgery showed a low risk of leakage in the two RCTs (Tsimoyiannis et al. [6] and Gadallah et al. [4]), various factors affect leakage. Risk factors related to leakage include not only the technique for PD placement, but also immediate PD initiation, dialysate 
Table 3 Laparoscopic surgery compared to open surgery for peritoneal dialysis catheter placement. Patient or population: peritoneal dialysis catheter placement; setting: in patients in Taiwan, Greece, the UK, China, Netherlands, and the USA; intervention: laparoscopic surgery; comparison: open surgery

\begin{tabular}{|c|c|c|c|c|c|}
\hline \multirow[t]{2}{*}{ Outcomes } & \multirow{2}{*}{$\begin{array}{l}\text { No. of } \\
\text { participants } \\
\text { (studies) } \\
\text { followed up }\end{array}$} & \multirow{2}{*}{$\begin{array}{l}\text { Certainty of } \\
\text { the evidence } \\
\text { (GRADE) }\end{array}$} & \multirow{2}{*}{$\begin{array}{l}\text { Relative effect ( } 95 \% \\
\text { Cl) }\end{array}$} & \multicolumn{2}{|l|}{ Anticipated absolute effects } \\
\hline & & & & Risk with open surgery & $\begin{array}{l}\text { Risk difference with } \\
\text { laparoscopic surgery }\end{array}$ \\
\hline Catheter survival & 424 (5 RCTs) & $\begin{array}{l}\oplus \oplus \circ \circ \\
l o w^{a, b, c}\end{array}$ & RR 1.02 (0.92 to 1.13 ) & 770 per 1000 & $\begin{array}{l}15 \text { more per } 1000 \\
\text { ( } 62 \text { fewer to } 100 \text { more) }\end{array}$ \\
\hline $\begin{array}{l}\text { Complications of catheter placement } \\
\text { (early complications: leakage) }\end{array}$ & 571 (7 RCTs) & $\begin{array}{l}\oplus \circ \circ \circ \text { very } \\
\text { low }^{a, c, d}\end{array}$ & RR 0.86 (0.25 to 3.02) & 81 per 1000 & $\begin{array}{l}11 \text { fewer per } 1000 \\
\text { (61 fewer to } 164 \text { more) }\end{array}$ \\
\hline $\begin{array}{l}\text { Complications of catheter placement } \\
\text { (late complications: hernia) }\end{array}$ & 391 (4 RCTs) & $\begin{array}{l}\oplus \circ O O \text { very } \\
\text { low } w^{c, e}\end{array}$ & RR 0.75 (0.21 to 2.72) & 31 per 1000 & $\begin{array}{l}8 \text { fewer per } 1000 \\
\text { ( } 24 \text { fewer to } 53 \text { more) }\end{array}$ \\
\hline $\begin{array}{l}\text { PD catheter-related infection } \\
\text { (exit site infection and tunnel infection) }\end{array}$ & 262 (4 RCTs) & $\oplus \oplus \circ \circ$ low $^{a, c}$ & RR 0.99 (0.43 to 2.29) & 83 per 1000 & $\begin{array}{l}1 \text { fewer per } 1000 \\
\text { (47 fewer to } 107 \text { more) }\end{array}$ \\
\hline Requirement for re-operation & $90(1 \mathrm{RCT})$ & $\begin{array}{l}\oplus \oplus \oplus \circ \\
\text { moderate }^{c}\end{array}$ & RR 0.96 (0.39 to 2.33) & 182 per 1000 & $\begin{array}{l}7 \text { fewer per } 1000 \\
\text { (111 fewer to } 242 \text { more) }\end{array}$ \\
\hline $\begin{array}{l}\text { Postoperative pain-the number of } \\
\text { patients complaining of pain }\end{array}$ & 127 (2 RCTs) & $\begin{array}{l}\oplus \circ O O \text { very } \\
\text { low }^{f, g, h}\end{array}$ & RR 1.05 (0.80 to 1.39) & 446 per 1000 & $\begin{array}{l}22 \text { more per } 1000 \\
\text { (89 fewer to } 174 \text { more) }\end{array}$ \\
\hline $\begin{array}{l}\text { Postoperative pain —assessed by a } \\
\text { pain scale }\end{array}$ & $45(1 \mathrm{RCT})$ & $\begin{array}{l}\oplus 000 \\
\text { very low } w^{f, g i}\end{array}$ & - & The mean pain scale was 0 & $\begin{array}{l}\text { MD } 1 \text { lower } \\
\text { (2.24 lower to } 0.24 \text { higher) }\end{array}$ \\
\hline $\begin{array}{l}\text { Hospitalization period associated with } \\
\text { catheter placement }\end{array}$ & 212 (3 RCTs) & $\begin{array}{l}\oplus 000 \\
\text { very low }\end{array}$ & - & $\begin{array}{l}\text { The mean hospitalization } \\
\text { period associated with } \\
\text { catheter insertion was } 0\end{array}$ & $\begin{array}{l}\text { MD } 0.83 \text { higher } \\
\text { ( } 0.04 \text { higher to } 1.61 \text { higher) }\end{array}$ \\
\hline Catheter migration & 526 (6 RCTs) & $\begin{array}{l}\oplus \oplus \oplus \circ \\
\text { moderate }^{a}\end{array}$ & RR 0.42 (0.18 to 0.96) & 120 per 1000 & $\begin{array}{l}69 \text { fewer per } 1000 \\
\text { (98 fewer to } 5 \text { fewer) }\end{array}$ \\
\hline $\begin{array}{l}\text { Catheter migration: limited to RCTs } \\
\text { containing laparoscopic surgery } \\
\text { without secured suture }\end{array}$ & 431 (4 RCTs) & $\begin{array}{l}\oplus \oplus \oplus \circ \\
\text { moderate }^{a}\end{array}$ & RR 0.58 (0.27 to 1.25$)$ & 103 per 1000 & $\begin{array}{l}43 \text { fewer per } 1000 \\
\text { ( } 75 \text { fewer to } 26 \text { more) }\end{array}$ \\
\hline $\begin{array}{l}\text { Catheter migration: limited to RCTs } \\
\text { containing laparoscopic surgery with } \\
\text { secured suture }\end{array}$ & 95 (2 RCTs) & $\begin{array}{l}\oplus \oplus \oplus \circ \\
\text { moderate }^{a}\end{array}$ & RR 0.09 (0.01 to 0.68 ) & 200 per 1000 & $\begin{array}{l}182 \text { fewer per } 1000 \\
\text { (198 fewer to } 64 \text { fewer) }\end{array}$ \\
\hline
\end{tabular}

GRADE Working Group grades of evidence: high certainty-we are very confident that the true effect lies close to that of the estimate of the effect; moderate certainty-we are moderately confident in the effect estimate: the true effect is likely to be close to the estimate of the effect, but there is a possibility that it is substantially different; low certainty-our confidence in the effect estimate is limited: the true effect may be substantially different from the estimate of the effect; very low certainty-we have very little confidence in the effect estimate: the true effect is likely to be substantially different from the estimate of effect

aThe randomization methods were not stated in three studies (Jwo et al [7], Xu et al. [8], Qiao et al. [9])

${ }^{b}$ Because there were studies with different intervention methods, i.e., peritoneoscopy, and there was concern about the outcome measurements, the rate of imprecision was lowered

${ }^{c}$ We evaluated on the assumption that the intervention choice differs with the difference in risk ratio of $2 \%$. The $95 \%$ Cl crossed the threshold, so we decided to lower the rate of imprecision

${ }^{d}$ Because of considerable heterogeneity $\left(I^{2}=52 \%\right)$, there was concern, and we decided to lower the level of inconsistency

${ }^{\mathrm{e}}$ All four studies were at high risk of bias from concerns with regards to allocation concealment

${ }^{f}$ The randomization method was not stated

gecause of the alternative outcome of quality of life

${ }^{h}$ We evaluated on the assumption that the intervention choice differs with a risk ratio difference of $10 \%$. The $95 \% \mathrm{Cl}$ crossed the threshold, and we decided to lower the rate of imprecision

'The details of the pain scale were not stated

${ }^{\mathrm{j}}$ Because there was a difference in hospitalized duration greater than 10 days among studies and the discharge standards were unclear, we decided to lower the level

${ }^{k}$ We assumed that the difference of three days hospitalization might facilitate the choice of intervention. The $95 \% \mathrm{Cl}$ does not cross the threshold, but it was

decided to lower by one level because the number of cases is small

volume used, and weakness of abdominal wall tissue, and the incidence is approximately $5 \%$ [31]. In particular, early fluid leakage within 30 days is affected by the catheter insertion site and immediate PD initiation. It is well known that the incidence of leakage is higher with a midline incision than a paramedian incision [32]. In an RCT by Tsimoyiannis et al. [6], $88 \%$ of patients who underwent open surgery had a catheter inserted through a midline incision, and PD was initiated within several days after surgery. On the other hand, in the RCT by Gadallah et al. [4], the catheter was inserted through a paramedian incision, and the break-in period was 17 days, but the incidence of leakage was $11.1 \%$. The incidence of leakage may be higher than in previous reports.

As in previous SRs and meta-analyses, there were no differences in catheter-related infections (exit site and tunnel infections) between laparoscopic surgery and open surgery. Antibiotic prophylaxis had been given to all patients in the four RCTs assessed for catheter-related infections. However, no RCT described the details of exit site 


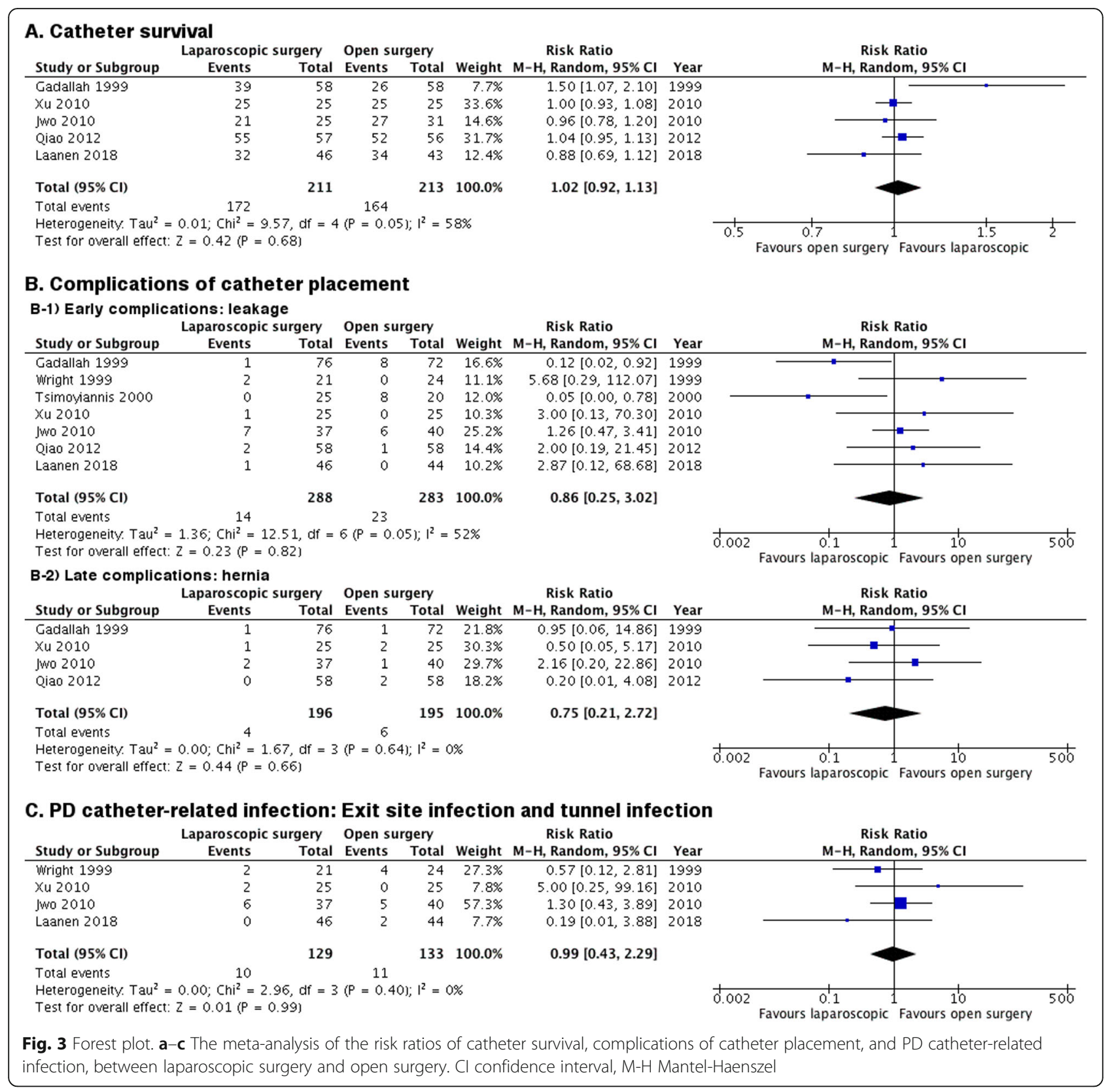

care after surgery, and the types of dressings and use of topical prophylactic antibiotics at the exit site were unclear. We consider that catheter-related infections are more affected by the location of the exit, daily exit site care, and immobilization of the catheter or patients' background characteristics (obesity, diabetes, or immunocompromised patient) than by differences in surgical procedures. In addition, the ISPD guidelines show that the effect of infectious complications on catheter survival beyond 30 days is more likely due to causes unrelated to the insertion procedure. However, many of the RCTs did not describe the onset of catheter-related infections.
Only one RCT evaluated the requirement for reoperation, and there was no difference by surgical procedure. According to clinical practice guidelines for peritoneal access published in 2010, the incidence of catheter dysfunction at the time of first use that requires catheter manipulation or replacement or results in technique failure should be less than $20 \%$ [11]. In the RCT by van Laanen et al. [10], the requirement for reoperation was $18.2 \%$ for open surgery and $17.4 \%$ for laparoscopic surgery, and both surgical procedures met audit criteria.

There have been no SRs and meta-analyses that compared postoperative pain according to differences in 


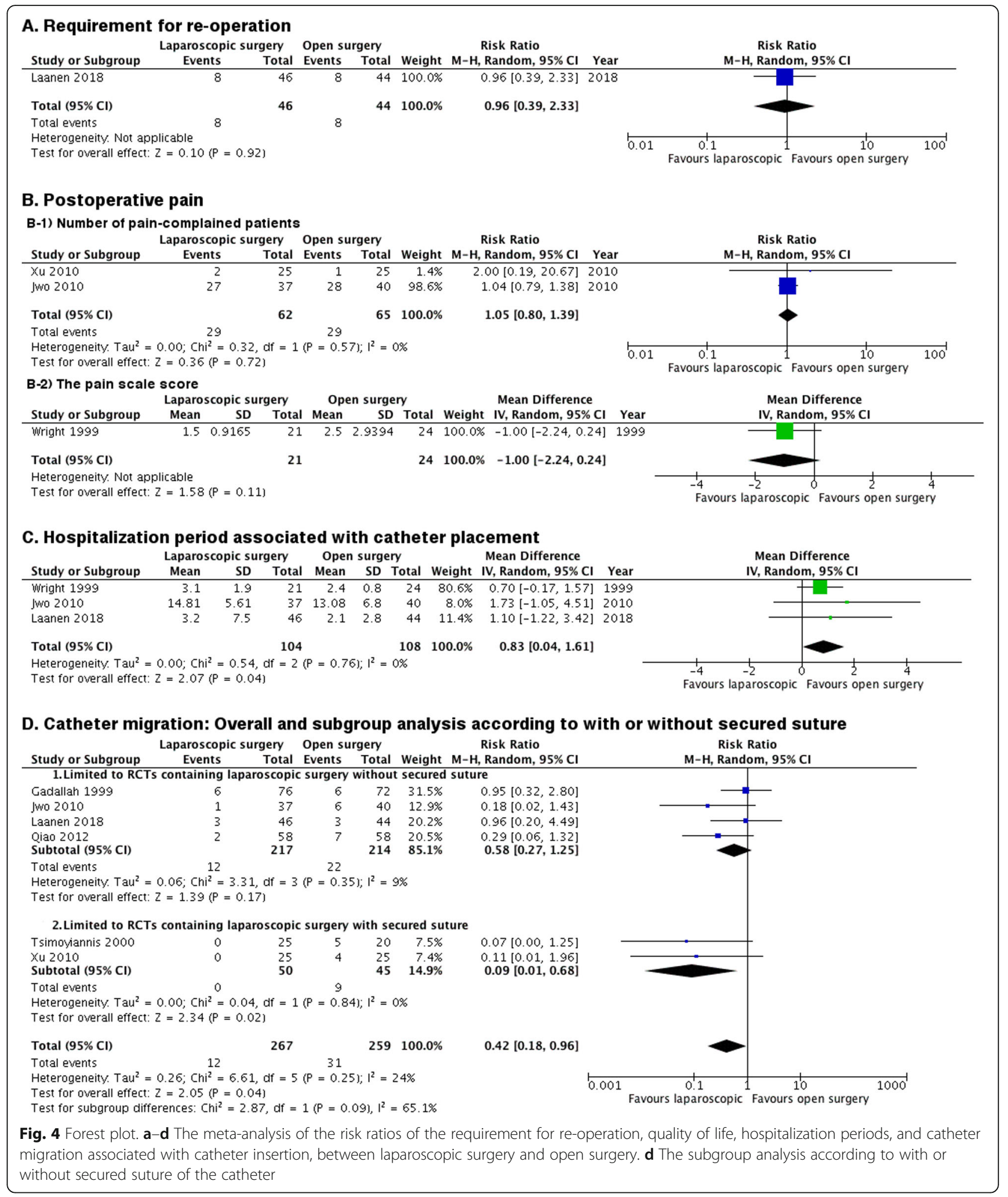

surgical procedures. Postoperative pain was compared in three RCTs, two of which compared the number of patients who complained of pain, and the other one compared the pain scale scores between the two groups.
There was no difference in pain due to the difference in surgical methods in the meta-analysis. In the first place, the patients' pain was subjective, the duration of the pain was unknown, and the statement on analgesic use was 
also inadequate. Allvin et al. reported that surgical technique (open surgery versus laparoscopic surgery) does not affect the quality of postoperative pain management during the first postoperative day if adequate analgesia is given [33]. It is an extremely important issue for quality of life (QOL) and needs to be clarified by many studies in the future.

Although SR and meta-analysis by Xie et al. compared the hospitalization period associated with catheter placement in the two groups, it was shown that there was no difference [26]. Unexpectedly, the present study showed that open surgery had significantly shorter hospitalization than laparoscopic surgery. The hospitalization period varied from $2-3$ days to 2 weeks depending on the study. There is a possibility that high heterogeneity may exist because the hospitalization period associated with catheter placement varies depending on the policy of the institution.

In three of the four SRs and meta-analyses, laparoscopic surgery was reported to reduce the risk for catheter migration [27-29]. However, these studies included observational studies. On the other hand, Xie et al. [26] analyzed catheter migration by meta-analysis including only RCTs, and they showed that there was no difference between the two groups. The present meta-analysis including six RCTs showed that laparoscopic surgery has a significantly lower incidence of catheter migration than open surgery. However, the significance diminished on limiting the analysis to RCTs involving laparoscopic surgery without secured suture of the PD catheter. In other words, secured suture of the catheter was shown to prevent catheter migration. However, ISPD guidelines do not recommend it because of the difficulty in removing the catheter from a firmly holding stitch. In addition, Ashegh et al. reported that catheter migration occurred in only $1.3 \%$ of cases even if the tip of the catheter was not fixed [34].

The present meta-analysis evaluated several outcomes using only randomized trials, including the latest RCT. In addition, the present study evaluated the outcome included pain and hospitalization period that affect the patient's QOL. The current guidelines also state that comparisons on advanced laparoscopic surgery, basic laparoscopic surgery, and open surgery are required. Recently, Shrestha et al. reported that catheter placement by advanced laparoscopic surgery is associated with significantly superior results compared to those of open surgery and basic laparoscopic surgery [35]. It is an interesting finding that although the advanced laparoscopic surgery was included in laparoscopic surgery group in this study, there was still no difference in primary outcome as compared to open surgery. In addition, it should be emphasized that the intraperitoneal fixation of the catheter in laparoscopic surgery contributed to the reduction of the risk of migration.
This study has some limitations. First, the definition of outcome was different in each of the RCTs. The definition of catheter survival was inconsistent across all studies, and assessment of catheter survival was short-term and may need to focus on long-term outcomes. Four of the seven RCTs did not mention whether the definition of leakage was also early or late phase. Even in the three RCTs where the definition of early leakage was given, the time periods considered early were not identical (i.e., 2 weeks, 4 weeks, or 6 weeks). Second, laparoscopic surgery included peritoneoscopic placement in the report by Gadallah et al. [4]. In other words, patients who were included in the laparoscopic surgery group did not all undergo the same procedure, leading to high heterogeneity. Third, the skills of the surgeon and the number of surgeries performed also affect the outcome. In an RCT by $\mathrm{Xu}$ et al. [8], open surgery was performed by nephrologists, and laparoscopic surgery was performed by surgeons. Furthermore, the RCT by Qiao et al. [9] was unclear on who performed the surgery. In Japan, many nephrologists have performed open surgery [36], but the safety has not been fully verified. Finally, the largest limitation is the small numbers of patients included in and low quality of the studies, which may not lead to reliable conclusions. Large-scale and high-quality RCTs are needed in the future.

In conclusion, the present findings indicate that laparoscopic surgery has a limited advantage over open surgery regarding the outcomes of PD patients. We would not specifically recommend performing laparoscopic surgery for PD catheter placement. In the future, we hope to conduct a comparative study of surgical procedure that focuses on patients' quality of life, with a clear definition of outcomes.

\section{Appendix}

The full electronic search strategies in the Cochrane Central Register of Controlled Trials and PubMed

(A) Primary search for systematic reviews and clinical practice guidelines in the Cochrane Central Register of Controlled trials and PubMed.

$(((($ Peritoneal Dialysis[MH]) OR ((periton*[tw] AND dialy*[tw]))) OR ((CAPD[tiab] OR CCPD[tiab] OR APD[tiab] OR TPD[tiab] OR (PD[tiab] AND (periton*[tw] OR dialy*[tw] $))))$ AND $(((($ laparoscop* $[$ tiab] OR peritoneoscop"[tiab] OR celioscop*[tiab]))) OR Laparoscopy[MH]) OR (((Catheters $[\mathrm{MH}])$ OR Catheterization[MH]) OR ((catheter[tiab] OR catheters[tiab] OR catheterization[tiab]))))) AND ((“Meta-Analysis"[PT] OR "meta-analysis"[TIAB]) OR ("Cochrane Database Syst Rev"[TA] OR "systematic review"[TIAB]) OR ("Practice Guideline"[PT] OR guideline[PT] OR "Practice Guidelines as Topic" $[\mathrm{MH}]$ OR (guideline*[TIAB] NOT medline[SB])))) 
(B) Secondary search for randomized controlled trials in PubMed.

((("Peritoneal Dialysis"[MH]) OR (periton"[TW] AND dialy*[TW]) OR (CAPD[TIAB] OR CCPD[TIAB] OR APD[TIAB] OR TPD[TIAB] OR (PD[TIAB] AND (periton"[TW] OR dialy"[TW])))) AND (((“Laparoscopy”[MH]) OR (laparoscop*[TIAB] OR peritoneoscop*[TIAB] OR celioscop"[TIAB])) OR ((“Catheters" [MH]) OR (“Catheterization" [MH]) OR (catheter[TIAB] OR catheters[TIAB] OR catheterization[TIAB])))) AND ((randomized controlled trial[pt] OR controlled clinical trial[pt] OR randomized[tiab] OR placebo[tiab] OR drug therapy[sh] OR randomly[tiab] OR trial[tiab] OR groups[tiab]) NOT (animals[mh] NOT humans[mh]))

\section{Acknowledgements}

Not applicable

\section{Authors' contributions}

TS, DK, KU, and AU mainly undertaken this review. The titles and abstracts were screened independently by TS and DK in the primary search for SRs and CPGs, and by KU and $A U$ in the secondary search for RCTs. HY and YT participated in the design of the study and performed the statistical analysis. MR and $\mathrm{YI}$ conceived of the study, and MT and HN participated in its design and coordination and helped to draft the manuscript. All authors read and approved the final manuscript.

\section{Funding}

Not applicable

\section{Availability of data and materials}

Data sharing not applicable to this article as no datasets were generated or analyzed during the current study.

Ethics approval and consent to participate

Not applicable

\section{Consent for publication}

Not applicable

\section{Competing interests}

The authors declare that they have no competing interests.

\section{Author details}

${ }^{1}$ Working Group on Revision of Peritoneal Dialysis Guidelines, Japanese Society for Dialysis Therapy, Tokyo, Japan. ${ }^{2}$ Division of Nephrology and Hypertension, Department of Internal Medicine, St. Marianna University School of Medicine, Kanagawa 216-8511, Japan. ${ }^{3}$ Department of Nephrology, Hitachi General Hospital, Ibaraki, Japan. ${ }^{4}$ Department of Nephrology, Kawasaki Saiwai Hospital, Kanagawa, Japan. ${ }^{5}$ Division of Endocrinology, Metabolism and Nephrology Department of Internal Medicine, Keio University School of Medicine, Tokyo, Japan. ${ }^{6}$ Department of Healthcare Epidemiology, School of Public Health, Graduate School of Medicine, Kyoto University, Kyoto, Japan. 'Department of Oral and Maxillofacial Surgery, National Hospital Organization Toyohashi Medical Center, Aichi, Japan. ${ }^{8}$ Division of Nephrology, Department of Internal Medicine, Tokyo Saiseikai Central Hospital, Tokyo, Japan. ${ }^{9}$ Department of Nephrology and Rheumatology, Aichi Medical University, Aichi, Japan. ${ }^{10}$ Clinical Engineering Research Center, Faculty of Medicine, Oita University, Yufu City, Japan.

${ }^{11}$ Department of General Internal Medicine, Saitama Medical University, Saitama, Japan.
Received: 24 June 2019 Accepted: 21 August 2019

Published online: 04 September 2019

\section{References}

1. Crabtree JH. Selected best demonstrated practices in peritoneal dialysis access. Kidney Int Supp/ 2006; 70:S27-7.

2. Bruhat MA, Chapron C, Mage G, Pouly JL, Canis M, Wattiez A, et al. The benefits and risks of laparoscopic surgery. (in French) Rev Fr Gynecol Obstet 1993; 88:84-8

3. Schlotterbeck H, Schaeffer R, Dow WA, Diemunsch P. Cold nebulization used to prevent heat loss during laparoscopic surgery: an experimental study in pigs. Surg Endosc. 2008;22:2616-20.

4. Gadallah MF, Pervez A, el-Shahawy MA, Sorrells D, Zibari G, McDonald J, et al. Peritoneoscopic versus surgical placement of peritoneal dialysis catheters: a prospective randomized study on outcome. Am J Kidney Dis. 1999;33:118-22.

5. Wright MJ, Bel'eed K, Johnson BF, Eadington DW, Sellars L, Farr MJ. Randomized prospective comparison of laparoscopic and open peritoneal dialysis catheter insertion. Perit Dial Int. 1999;19:372-5.

6. Tsimoyiannis EC, Siakas P, Glantzounis G, Toli C, Sferopoulos G, Pappas M, et al. Laparoscopic placement of the Tenckhoff catheter for peritoneal dialysis. Surg Laparosc Endosc Percutan Tech. 2000;10:218-21.

7. Jwo SC, Chen KS, Lee CC, Chen HY. Prospective randomized study for comparison of open surgery with laparoscopic-assisted placement of Tenckhoff peritoneal dialysis catheter--a single center experience and literature review. J Surg Res. 2010;159:489-96.

8. Xu T, Zang L, Xie JY, Mao ZH, Ma XH, Huang XM, et al. Efficacy and safety of laparoscopic and conventional placement of peritoneal dialysis catheters in patients with ESRD. J Nephrol Dialy Transplant. 2010;19:430-4.

9. Qiao Q, Lu GY, Xu DY, Zhou XJ, Li L. A comparison of two methods for catheterization in peritoneal dialysis. Jiangsu Med J. 2012;38:2812-4.

10. van Laanen JHH, Cornelis T, Mees BM, Litjens EJ, van Loon MM, Tordoir $J H M$, et al. Randomized controlled trial comparing open versus laparoscopic placement of a peritoneal dialysis catheter and outcomes: The CAPD I Trial. Perit Dial Int. 2018;38:104-12.

11. Figueiredo A, Goh BL, Jenkins S, Johnson DW, Mactier R, Ramalakshmi S, et al. International Society for Peritoneal Dialysis. Clinical practice guidelines for peritoneal access. Perit Dial Int. 2010;30:424-9.

12. Strippoli GF, Tong A, Johnson D, Schena FP, Craig JC. Catheter type, placement and insertion techniques for preventing peritonitis in peritoneal dialysis patients. Cochrane Database Syst Rev. 2004;4 CD004680.

13. Higgins JPT, Green S. The Cochrane Collaboration: Cochrane Handbook for Systematic Reviews of Interventions Version 5.1.0; Available at: www. cochrane-handbook.org.

14. Higgins JP, Thompson SG, Deeks JJ, Altman DG. Measuring inconsistency in meta-analyses. BMJ. 2003;327:557-60.

15. Guyatt G, Oxman AD, Akl EA, Kunz R, Vist G, Brozek J, et al. GRADE guidelines: 1. Introduction-GRADE evidence profiles and summary of findings tables. J Clin Epidemiol. 2011;64:383-94.

16. Gajjar AH, Rhoden DH, Kathuria P, Kaul R, Udupa AD, Jennings WC. Peritoneal dialysis catheters: laparoscopic versus traditional placement techniques and outcomes. Am J Surg. 2007;194:872-5.

17. Mattioli G, Castagnetti M, Verrina E, Trivelli A, Torre M, Jasonni V, et al. Laparoscopic-assisted peritoneal dialysis catheter implantation in pediatric patients. Urology. 2007;69:1185-9.

18. Soontrapornchai $P$, Simapatanapong T. Comparison of open and laparoscopic secure placement of peritoneal dialysis catheters. Surg Endosc. 2005;19:137-9.

19. Crabtree JH, Fishman A. A laparoscopic method for optimal peritoneal dialysis access. Am Surg. 2005;71:135-43.

20. Oğünç G, Tuncer M, Oğünç D, Yardimsever M, Ersoy F. Laparoscopic omental fixation technique versus open surgical placement of peritoneal dialysis catheters. Surg Endosc. 2003:17:1749-55.

21. Daschner M, Gfrörer S, Zachariou Z, Mehls O, Schaefer F. Laparoscopic Tenckhoff catheter implantation in children. Perit Dial Int. 2002;22:22-6.

22. Batey CA, Crane JJ, Jenkins MA, Johnston TD, Munch LC. Mini-laparoscopyassisted placement of Tenckhoff catheters: an improved technique to facilitate peritoneal dialysis. J Endourol. 2002;16:681-4.

23. Crabtree JH, Fishman A. A laparoscopic approach under local anesthesia for peritoneal dialysis access. Perit Dial Int. 2000;20:757-65.

24. Draganic B, James A, Booth M, Gani JS. Comparative experience of a simple technique for laparoscopic chronic ambulatory peritoneal dialysis catheter placement. Aust N Z J Surg. 1998;68:735-9. 
25. Eklund B, Groop PH, Halme L, Honkanen E, Kala AR. Peritoneal dialysis access: a comparison of peritoneoscopic and surgical insertion techniques. Scand J Urol Nephrol. 1998;32:405-8.

26. Xie H, Zhang W, Cheng J, He Q. Laparoscopic versus open catheter placement in peritoneal dialysis patients: a systematic review and metaanalysis. BMC Nephrol. 2012;13:69.

27. Hagen SM, Lafranca JA, Steyerberg EW, IJzermans JN, Dor FJ. Laparoscopic versus open peritoneal dialysis catheter insertion: a meta-analysis. PLoS One. 2013;8:e56351.

28. Chen Y, Shao Y, Xu J. The survival and complication rates of laparoscopic versus open catheter placement in peritoneal dialysis patients: a metaanalysis. Surg Laparosc Endosc Percutan Tech. 2015;25:440-3.

29. Qiao Q, Zhou L, Hu K, Xu D, Li L, Lu G. Laparoscopic versus traditional peritoneal dialysis catheter insertion: a meta analysis. Ren Fail. 2016;38:838-48.

30. Crabtree JH, Shrestha BM, Chow KM, Figueiredo AE, Povlsen JV, Wilkie M, et al. Creating and maintaining optimal peritoneal dialysis access in the adult patient: 2019 UPDATE. Perit Dial Int. 2019 Apr 26. pii: pdi.2018.00232. https:// doi.org/10.3747/pdi.2018.00232.

31. Leblanc M, Ouimet D, Pichette V. Dialysate leaks in peritoneal dialysis. Semin Dial. 2001;14:50-4.

32. Spence PA, Mathews RE, Khanna R, Oreopoulos DG. Improved results with a paramedian technique for the insertion of peritoneal dialysis catheters. Surg Gynecol Obstet. 1985;161:585-7.

33. Allvin R, Rawal N, Johanzon E, Bäckström R. Open versus laparoscopic surgery: does the surgical technique influence pain outcome? Results from an international registry. Pain Res Treat. 2016;2016:4087325. https://doi.org/1 0.1155/2016/4087325.

34. Ashegh H, Rezaii J, Esfandiari K, Tavakoli H, Abouzari M, Rashidi A. One-port laparoscopic technique for placement of Tenckhoff peritoneal dialysis catheters: report of seventy-nine procedures. Perit Dial Int. 2008;28:622-5.

35. Shrestha BM, Shrestha D, Kumar A, Shrestha A, Boyes SA, Wilkie ME. Advanced laparoscopic peritoneal dialysis catheter insertion: systematic review and meta-analysis. Perit Dial Int. 2018:38:163-71.

36. Ikeda M, Terawaki H, Kanda E, Furuya M, Tanno Y, Nakao M, et al. Interventional nephrology: current status and clinical impact in Japan. Clin Exp Nephrol. 2018;22:437-47.

\section{Publisher's Note}

Springer Nature remains neutral with regard to jurisdictional claims in published maps and institutional affiliations.

Ready to submit your research? Choose BMC and benefit from:

- fast, convenient online submission

- thorough peer review by experienced researchers in your field

- rapid publication on acceptance

- support for research data, including large and complex data types

- gold Open Access which fosters wider collaboration and increased citations

- maximum visibility for your research: over $100 \mathrm{M}$ website views per year

At BMC, research is always in progress.

Learn more biomedcentral.com/submissions 